\title{
Reality or Lie: Discussing Whether New Media Really Empower Citizens
}

\author{
Tiancong $\mathrm{Hu}$ \\ University of East Anglia \\ Norwich, the United Kingdom \\ hutiancong0406@163.com
}

\begin{abstract}
With the change of communication modes, new media give every citizen the right to express himself and further change the political and ecological environment of the whole world. But do the new media give citizens real power? It may be too early to judge. Based on the above ideas, this paper mainly sorted out the development of new media and its impact on society by literature method and came to the conclusion that "new media may not truly empower citizens". It is true that the new media has brought about the rise of grassroots culture, promoted the supervision of public opinion and given citizens more autonomy. However, a series of resulting negative effects, such as the leakage of personal privacy, the flood of fake news and network monitoring, are also important to be focused.
\end{abstract}

\section{Keywords-New media; Citizens; Give; Damage}

\section{INTRODUCTION}

New media, as the concept compared to traditional media, is a media form that is based on computer information processing technology, including BBS, blogger, smartphones, network, digital television, and so on. The greatest feature is that it is free of time and space, in addition, it is an up-to-date and interactive media form. People can break through the existing boundaries of time and space to obtain and deliver information at any time in a relatively equal virtual world and interactive space. Every country's constitution prescribes the right of citizens to express, such as speech, punishment or assembly. But because of the objective reality of different countries, such as economic level or social structure, the exercise of civil rights is very limited. The emergence of new media can change this phenomenon. The empowerment of new media that is represented by the Internet does not give people power itself because of its own technical and propagation characteristics. But it can empower citizens expression rights, it can help people perform the power of speech on a larger level. In the real life, the disadvantaged groups at the bottom of the society are always lack of rights and ability to protect their rights and interests because of the differentiation of social interests and institutional arrangements. We should redistribute power if we want to change this condition [1]. New media empowerment enables disadvantaged groups to grasp social resources and their own destiny on a larger level by their own participation and inspire their potential to get more social change.
There is no doubt that the development of new media that brought about by the technological revolution is rapidly changing our lives, and it is occupying our daily life at unexpected speed. Television has reached the reach of 50 million people in 13 years, but it took four years for the Internet to reach this number, however, iphone and ipad took only two years to get this coverage [2]. New media has not only changed the way that information is transmitted, speed or content, but it has begun to affect many aspects in our social life. For example, as one of the most important and well-known forms of new media, the Internet has become a gathering place of thought and culture and a magnifying glass of public opinion The social influence of new media represented by the Internet cannot be ignored. So, many people believe that new media gives users more freedom and power. According to some existing circumstances, this statement is not without merit.

\section{NeW Media ENPOWER CitizenS}

\section{A. Rise of grassroots culture}

With the rapid development of new media that use interactivity as one of the main characteristics, such as the network, the public has more right of speech. New media provides individuals with greater voice space and more opportunities to present themselves, for example, the rise of grassroots culture. This cultural form is essentially the expression way by common people and even the disadvantaged groups. In traditional media, they stand at the end of public discourse. But new media can provide a stage for them to show themselves, for instance, Hip-hop has been embraced by more and more audiences and mainstream media. This form of music that created by the black people of the American rock-bottom society in the last century has been accepted worldwide, even have their own TV shows. They can show themselves and participate in social interaction through the Internet. According to Dong, the Internet has trumpeted the grassroots culture. In his opinion, there is an inseparable connection between grassroots culture and new media [3]. The new media provides a huge place for the grassroots through a variety of platforms, such as blog, BBS, Facebook, and YouTube. The interactivity and anonymity of new media give users with the possibility of freedom expression and getting the right of speech. 


\section{B. Strengthen public opinion supervision}

Secondly, in the age of traditional media, although citizens are nominally endowed with the power of public opinion supervision, there is no possibility to execute this power actually. However, nowadays, it is becoming more and more normal for citizens to exercise the right of supervision through new media, especially the Internet. According to White's theory, citizens' supervision of the government is essential. But in the past, that power was hard to come true. However, at present, when there are public crisis events and social hot topics in society, citizens can use the power of new media to supervise government decisions. The act of collecting, reporting, analyzing, and distributing news or information by individual or group of citizens aims to provide independent, credible, accurate, and extensive information that a democratic society needs [4]. The new media has broken the monopoly pattern of traditional news communication organizations and improved the social public domain. In addition, lots of traditional media have also begun to break the original institutional boundaries and assume the responsibility of public opinion supervision.

\section{Enhance user autonomy}

Finally, new media gives users more autonomy. The new media communication mechanism can make users to have a greater choice in information consumption, content production and acceptance. Each individual user is his or her own transmission center. They can build their own information networks [5]. In addition, according to Goffman, in real life, as the social role, we have to maintain a relatively stable state to perform in front of other audiences, and this is an important difference between human self and social self [6]. However, this stable state can be broken to some extent in virtual space. This is because that people can show their human self in an anonymous environment. A virtual and anonymous environment make people feel more relaxed, so they conduct self-presentation more freely. And people's performance space is diverse. They can move to other spaces if they fail in an original space. In other words, the role of new media users can be unrestricted by the social environment. With the help of new media platforms, individual users control and manage the socialized interactive process and result more autonomously.

\section{New Media Damage Citizens Power}

In a nutshell, in the new media era, network is the most representative information diffusion space, and the emergence of the Internet has greatly expanded the individuals living environment and extended the human vision. However, the development of the Internet has also brought about many social problems. Do new media, represented by the Internet, really give users more power? On the other hand, it also infringes on users' power.

\section{A. Disclosure of personal privacy}

For instance, it is easy to get others personal information, secret and privacy because of the convenience of the Internet. It would pose a serious threat to the protection of civil rights. With the help of modern science and technology, privacy is copied and disseminated like any other information. The ability is almost limitless to replicate and spread. The original purpose of science and technology development was to make life more convenient. But when those who have ulterior motives use it, there is a problem of technological tyranny. Technology is not only a tool for human existence and development, but also a self that means to achieve its purpose by itself [7]. When technology develops beyond human imagination, they will face ethical and moral challenges. Nowadays, a great number of consumers are using the Internet. If people want to use the Internet, they will inevitably fill out personal data in various website services. But the personal information that they submitted is not secured. Take China alone as an example, this is one of the places where the Internet is growing rapidly and prospering, but at the same time, the leak of personal information and the invasion of citizen privacy are quite serious. According to a report released by the China Internet association in 2016, 78.2 percent of Internet users' personal identities were compromised in the past year, and 63.4 percent of netizens' personal online activity information was leaked. In addition, Internet users lost about 80.5 billion yuan due to personal information disclosure, spam and fraud information, and 45 million of them have suffered economic losses of more than 1,000 yuan [8]. And when the media uses the Internet to infringe on citizens' privacy, as Prosser sums up and writes in the US tort law, man-made false lights are created. Prosser states that incorrect or untruthful information may lead to a person suffering from sympathy, ridicule or contempt, and even causing physical and mental harm [9]. Some media still disclose and expose private information without the permission of the user and verifying the authenticity of the content. This exposure has nothing to do with the public interest, but it can just the way of media that attract eyeballs and increase advertising income. This practice may lead to misunderstanding by others and infringe on their personal life.

\section{B. A flood of fake news}

In addition, because new media have given the public more oversight power, the number of participants has greatly increased in many platforms on account of low threshold, open and anonymity. In the public opinion supervision of traditional media, there are many gatekeepers, such as professional authors, scholars and editors. But in the new media era, it is easy for most people to participate in supervision. Though platforms can be technically used to screen content by setting keywords and other methods, comments and criticisms will still come in like the tide on the Internet when a hot event occurs. It reduces the rationality and seriousness of public opinion supervision and lead to a flood of online rumors. Some people publish and disseminate fake news because of economic benefits. When it comes to power, the consequences are even worse. In September this year, Facebook's chief security executive Stamos said in a statement on newsroom website that in the examination process of web advertising, there are about 470 fake accounts that put amount of about 3000 political 
advertising for the value of $\$ 100000$ [10]. More than a dozen days later, CNN reported that Russia had used fake news on Facebook in the 2016 US election to disrupt the election [11]. Fake information has been published and disseminated, which has affected many citizen's judgment and cognition through new media platforms, especially social media. More seriously, most users are not directly involved in the event in the process of public opinion supervision. Many people produce public opinion with lots of reprint and commentary, which often leads to emotional response. Extreme attitudes can easily lead to distorted news and even cyber-violence. In 2006, the Megan incident became the first case of cyber-violence in the United States and received widespread attention. Except main responsible person, Laurie drew, a large number of Internet users were also involved in the humiliation of Megan Meier without being aware of true facts [12]. According to Le Bon, sometimes, thousands of isolated individuals acquire the characteristics of a psychological group under certain violent emotions. In this case, an accidental event would be enough to bring them together and acquire the attributes of group behavior immediately [13]. The purpose of public opinion supervision is that citizens want to protect the morality and ensure their right to know and new media give them the opportunity and help, but when this power is abused, there are lots of irregularities and even illegal behaviors. Instead of giving users more power, the new media infringes their power.

\section{Irrational audiences}

Furthermore, there is no doubt that the new media has brought about a good change in government and civil relations. But in practice, the relationship between them still has a series of problems. First of all, some governments ignore public demand and intervene society in excess. Although this phenomenon has improved since the new media era, there is still a phenomenon of excessive government intervention in life, and it makes that it impossible for media workers to be independent. And the privilege and corruption of some government officials can also hamper the transparency of government information. In addition, citizens often play irrational roles in political life because of the difference between education and the way of thinking. Le Bon believes that this is mainly caused by group psychological characteristics. He states that the group has the characteristics of irresponsibility, infectiousness and suggestibility, which can make citizens irrational participation in political life. Because of the audience emotional, many people with ulterior motives in cyberspace rally the masses to spread information, incite emotions and organize action. So, they can expand influence and get more resources. But it is harmful to society. For example, in last year election in US, some stars used influence to call on their fans to vote for a candidate, further exacerbating divisions in American society. As Ross said, the virtual technology makes the government act at any time under the supervision of the public and the government's internal affairs and diplomacy more and more transparent [14]. However, as the communication carrier of social information, the media inevitably has political significance since its birth.

\section{Ubiquitous network monitoring}

At last, ubiquitous network monitoring is also a big problem. The development of economy has prompted people to improve their sense of security and defense constantly. When traditional local analogue monitoring methods gradually fail to meet the demand of certain industries and remote monitoring, the monitoring mode of remote transmission through the network will be generated. When Internet surveillance becomes the norm, people are exposed to other people's cameras all the time, and every move in their daily life is monitored. According to a science website called ZDNet, some of the leaked secret documents show that the CIA has been hacking homes, offices and public wi-fi routers in many years. Their aim is to keep secret surveillance of people in real time. The documents are part of a document leaked by WikiLeaks. In fact, routers have long been the main target of intelligence agencies and hackers, because it is the main hub of the entire network [15]. In addition to the intelligence agencies, the government is also secretly monitoring citizens through the Internet. Edward Snowden, the former NSA employee, exposed the policy that the US government agency secretly collected data to monitor citizens' phones in 2013 [16]. The NSA monitored almost every phone record that called in the United States and compares it with known terrorist information. Through this program, the government got a lot of data, including phone numbers, call times and call locations. More seriously, there are some obvious drawbacks to the video monitoring of traditional wired networks, so wireless video monitoring, which allows monitoring to get rid of restrictions further, has been used more widely in recent years. The development of technology and new media has not really given users more freedom and protected their rights. On the contrary, they become surveillance tools and platforms.

\section{CONCLUSION}

On the face of it, new media seem to give users more autonomy and freedom to exercise their power. On the other hand, however, the development of technology also reinforces its negative effects. At the beginning of the Internet popularization, Dyson states that the website can bring profound changes to human institutions, but it does not have any impact on humanity [17]. The empowerment of new media is a complete lie when new media plays a role in the infringement of civil rights, such as fake news, cyber violence or network surveillance. The emergence of new media has upended the benign ecology of traditional Internet, civil and social rights, and many infringement and violence also destroy the orderly civil society development. The abuse of new media by some government agencies and social institutions make it as a platform to monitor ordinary citizens and consumers. In short, it is too early to conclude that new media can give users more power. Everyone should think that a question that how to maximize the role of new media. 


\section{REFERENCES}

[1] Gutiérrez L M, Delois K A, and Glenmaye L. (1995) 'Understanding empowerment practice: Building on practitioner-based knowledge', Families in Society the Journal of Contemporary Human Services, 76(9), pp. 534-542.

[2] An Ever-Changing World (2009) Available at: https://www.youtube.com/watch?v=yuKu6PZXCIY (Accessed 15 November 2017).

[3] Dong, Y. (2008) 'Internet and network grassroot culture', China Media Technology, 2008(3), pp. 36-37

[4] Bowman, S. and Willis, C (2003) We Media: How Audiences are Shaping the Future of News and Information. Reston: The American Press Institute Conducts.

[5] Peng, L (2015) New media users: more active or more passive, Modern Communication, 2015(5), pp.12-15.

[6] Goffman, E. (2016) The Presentation of Self in Everyday Life. Beijing: Beijing University Press.

[7] Berry, T. (1988) The Dream of the Earth. San Francisco: Sierra Club Books.

[8] A report on the protection of Internet users' rights in China (2015) Available http://www.scio.gov.cn/zhzc/8/5/Document/1441916/1441916.htm (Accessed 19 November 2017) .

[9] American Law Institute (2000). Restatement of the Law, Torts: Apportionment of Liability, as Adopted and Promulgated.

[10] Stamos, A. (2017) An Update on Information Operations on Facebook. Available at: https://newsroom.fb.com/news/2017/09/informationoperations-update/ (Accessed 21 November 2017).

[11] Raju, M. and Herb, J. (2017) Mark Warner: How did Russians know who to target on Facebook? Available at: http://edition.cnn.com/2017/09/26/politics/senate-intelligencecommittee-russia-facebook-ads/index.html (Accessed 21 November 2017).

[12] Megan's story (2006) Available at: https://www.meganmeierfoundation.org/megans-story.html (Accessed 21 November 2017).

[13] Le Bon, G. (2009) The Crowd: A Study of the Popular Mind. London: Sparkling Books.

[14] Ross, E. (1930) Principles of Sociology. New York: Century press.

[15] Whittaker, Z. (2017) CIA has been hacking into Wi-Fi routers for years, leaked documents show. Available at: http://www.zdnet.com/article/ciahas-been-hacking-into-wi-fi-routers-for-years-leaked-documents-show/ (Accessed 30 November 2017).

[16] The Guardian (2013) NSA collecting phone records of millions of Verizon customers daily. Available at: https://www.theguardian.com/world/2013/jun/06/nsa-phone-recordsverizon-court-order (Accessed 30 November 2017).

[17] Dyson, E (1997) Release 2.0: A Design for Living in the Digital Age. New York: Broadway Books. 